\title{
Cultura política (concepto e imaginarios sociales)*
}

\author{
Political culture (concept and social \\ imaginaries)
}

\author{
Rodrigo Escribano Roca \\ Centro de Estudios Americanos, Universidad Adolfo Ibáñez \\ Instituto Universitario de Investigación en Estudios Latinoamericanos, Universidad de Alcalá \\ ORCID ID 0000-0002-6405-7191 \\ rodrigo.escribano@uai.cl
}

\section{Cita recomendada:}

Escribano Roca, R. (2021). Cultura política (concepto e imaginarios sociales). Eunomía. Revista en Cultura de la Legalidad, 20, pp. 272-291.

doi: https://doi.org/10.20318/eunomia.2021.6077

Recibido / received: 21/07/2020

Aceptado / accepted: 28/12/2020

\section{Resumen}

La entrada ofrece un itinerario complementario al trabajo de Andrea Greppi, abordando la categoría de 'cultura política' desde la teoría de la historia, la historiografía intelectual, los análisis de los imaginarios sociales, los estudios de los nacionalismos y la historia internacional. En primer lugar, se ofrecerá un excurso sobre su adopción en la historiografía y los estudios culturales, acompañándolo con una definición sintética del término. Luego se procederá a evaluar sus virtudes epistémicas, exponiendo sus aplicaciones en la historiografía reciente y las ventajas epistemológicas que ha comportado. Más adelante, la entrada incorporará tres secciones propositivas. La primera postulará relacionar la categoría con el estudio de las ideologías políticas y los imaginarios sociales, como vía para delimitar las escalas de los actores grupales analizables. La segunda ofrecerá un modelo heurístico para optimizar el análisis de las culturas políticas en base a su relación con la categoría de 'conciencia histórica'. Finalmente, se valorarán las potencialidades que ofrecen las relaciones entre el concepto abordado y dos campos de tanta relevancia como los estudios sobre el nacionalismo y la teoría de las relaciones internacionales.
\end{abstract}

\section{Palabras clave}

Cultura política, imaginario social, conciencia histórica, visiones de lo global, ideología, Historia política.

\footnotetext{
* Este trabajo se ha realizado con el apoyo del Programa On Trust-CM H2019/HUM-5699, financiado por la Comunidad de Madrid y el Fondo Social Europeo; asimismo, en el marco del Fondecyt de Iniciación "La Expedición del Pacífico y la Guerra hispano-sudamericana en los imaginarios geopolíticos de la España liberal (1860-1866)", financiado por la Agencia Nacional de Investigación y Desarrollo. Ministerio de Ciencia, Tecnología, Conocimiento e Innovación de Chile, con referencia: Fondecyt N 112000245.
} 


\begin{abstract}
The entry offers a complementary itinerary to the work of Andrea Greppi, addressing the category of 'political culture' from the theory of history, intellectual historiography, the analysis of social imaginaries, the studies of nationalisms and international history. In the first place, the paper offers a review on its adoption in historiography and cultural studies, accompanying it with a synthetic definition of the term. Then we will proceed to evaluate its epistemic virtues, exposing its applications in recent historiography and the epistemological advantages it has brought. Later, the post will incorporate three propositional sections. The first will postulate a dialogue between the category and the theoretical background of the study of political ideologies and social imaginaries, as a way to delimit the scales of analyzable group actors. The second will offer a heuristic model to optimize the analysis of political cultures based on their relationship with the category of 'historical consciousness'. Finally, we will address the potentialities offered by the application of the concept to two fields of such relevance as studies on nationalism and the theory of international relations.
\end{abstract}

\title{
Keywords
}

Political culture, social imaginary, historical conscience, global vision, ideology, Political history.

\begin{abstract}
SUMARIO. 1. Cultura Política: raíces historiográficas y definición preliminar. 2. Las virtudes epistémicas. 3. Actores y escalas: subculturas políticas, ideologías e imaginarios sociales. 4. Conciencia Histórica y cultura política: un modelo heurístico. 5. Culturas políticas, nacionalismos y visiones de lo global. 6. Conclusión.
\end{abstract}

\section{Cultura Política: raíces historiográficas y definición preliminar}

El concepto fue formulado originalmente en el ámbito de la ciencia política por Almond y Verba (2016 [1963]). Estos definieron la cultura política como el conjunto de orientaciones cognitivas, afectivas y evaluativas respecto del sistema político que compartían los miembros de una sociedad. Más allá de las múltiples mutaciones y aplicaciones que ha tenido la categoría y de su notable auge en el campo de la teoría política (Greppi, 2021) ${ }^{1}$ hace tres décadas que se ha abierto camino progresivamente en la historiografía. De hecho, es posible afirmar que la categoría se ha consolidado como vía que permite combinar exitosamente la historia intelectual, la historia política, la historia social y los estudios culturales.

La popularización creciente del concepto deriva, en buena medida, de las necesidades convergentes de renovación que estas subdisciplinas experimentaron a partir de las últimas décadas del siglo XX. La nueva historia intelectual emergida del giro lingüístico se vio impelida a reformar los marcos epistémicos abiertamente teleológicos que habían imperado en la vieja historia de las ideas (Lovejoy, 1983 [1936] $)^{2}$, tratando de entender los contextos sociopolíticos, los vocabularios y las dinámicas de poder que enmarcaban los sistemas de pensamiento de los autores y corrientes abordados (Baring, 2016, pp. 48-60). Por su parte, muchos cultivadores de la historia política buscaban trascender el carácter marcadamente individualista, institucionalista y elitista de los objetos de estudio consagrados por la subdisciplina

\footnotetext{
${ }^{1}$ La entrada de Greppi, que acompaña a la presente, ofrece una descripción rica y sistemática de la evolución del concepto en el seno de la teoría política.

2 Lovejoy y sus seguidores tendían a entender las grandes ideas políticas como entidades autorrealizadas que, tras ser enunciadas por los pensadores canónicos, se habían proyectado y perpetuado espontáneamente en la conciencia social. En este contexto, las ideas se constituirían como entidades atemporales y sujetos históricos independientes de sus contextos de enunciación.
} 
(Pedersen, 2007, pp. 36-56). Mientras tanto, los historiadores sociales aspiraban a incorporar los análisis semióticos popularizados por el «giro cultural» ${ }^{3}$ sin renunciar a su agenda de indagación, de corte materialista, en torno a las grandes tendencias socioeconómicas y demográficas que habían modelado el mundo contemporáneo (Sewell, 2006, pp. 89-110).

El progresivo triunfo de la categoría se concretó en un camino de ida y vuelta. Por un lado, estuvo estrechamente vinculado a la asunción de las técnicas de la antropología cultural y la teoría literaria. Estas operaron como horizontes teoréticos de sustitución ante el quiebre posmoderno de la confianza en los marcos analíticos positivistas y estructuralistas, que desde el siglo XIX habían aspirado a formular teorías generales que mimetizasen el modelo de las ciencias experimentales (Roberts, 2017, pp.114-126). Por otro lado, como explica Keith Baker (2006, pp. 105-108), el estudio de las culturas políticas parecía evadir los excesos semióticos de los estudios culturales, en tanto que demandaba entender los sistemas institucionales, los contextos sociales y las materialidades en las que se enmarcaban los entramados simbólicos estudiados.

En este punto es arriesgado pero útil plantear una acepción preliminar de carácter general de la categoría que nos ocupa a partir de algunos trabajos punteros que han analizado su desarrollo paradigmático (e.g. Tong, 2019, pp. 1-10) ${ }^{4}$. En síntesis, estos tienden a conceptualizar la cultura política como el conjunto de experiencias, expectativas, símbolos e ideas que modelan las conductas políticas, las identificaciones grupales y las pautas de acción colectiva de los actores sociales que interactúan en el seno de un sistema político determinado (e.g. Berstein, 1999, pp. 390-393). La categoría abarca tanto los sistemas representacionales que configuran las creencias de los grupos estudiados como los comportamientos políticos derivados de los mismos (e.g. Romeo y Sierra, 2014, pp. 11-18). Es decir, el término implica la disección del conjunto de discursos, prácticas de poder y modos de sociabilidad en que se traducen los entramados simbólicos compartidos por los sujetos analizados (Morán, 2010, pp. 110-119). Por consiguiente, la expresión de cultura política, en buena medida gracias a su laxitud semántica, conjuga dos dimensiones complementarias. Por un lado, hace referencia a las visiones generales del mundo y a los códigos valóricos que estructuran el marco de relaciones políticas de un grupo o una sociedad dados. Por otra, refiere cómo ese sistema de símbolos, racionalidades y hábitos de pensamiento establece una relación recíproca de causalidad con las condiciones materiales de existencia de los individuos, estructurando sus intereses y sus motivaciones y, por tanto, su relación con el medio social y el sistema político de los cuales forman parte constitutiva (Cabrera, 2010, pp. 23-25). Esta dualidad de acepciones hace que el concepto de cultura política deba lidiar con lo que Stephen Welch ha llamado una ontología dualística: la dialéctica entre una dimensión discursiva o simbólica y otra práctica o performativa (Welch, 2013, pp. 152-155).

Esta definición tan laxa y transversal de la cultura política es la que, con evidentes fluctuaciones, ofrece un sustrato común a las copiosas reflexiones académicas que la emplean. Dada la amplitud significativa del término, no es casual que el gran peligro que detectan sus teóricos es que este pierda su utilidad heurística como consecuencia del sobreuso y de la indefinición. Es por ello que algunos de los

\footnotetext{
${ }^{3}$ Particularmente la herramienta metodológica de la thick description enunciada por Cliford Geertz, el cual entiende que el ser humano está inserto en tramas culturales de significado que deben ser abordadas en base a un ejercicio de interpretación hermenéutica alejado de los postulados del positivismo.

${ }^{4}$ Algunos, como Dezhi Tong, defienden que, si bien el significante "cultura política» es de acuñación reciente, remite a un concepto de empleo muy extendido, que se remontaría a las teorizaciones grecorromanas, confucianas, cristianas y modernas en torno a la relación entre el poder político, los modelos éticos y los hábitos sociales.
} 
adalides de la categoría, como Serge Berstein, han realizado ejercicios de acotación conceptual. Según el historiador francés, para que exista una cultura política analizable como tal deben operar ciertos requisitos básicos: una colectividad reconocible, referentes históricos y míticos universalmente admitidos por sus miembros, valores comunes, principios filosóficos compartidos y una visión general del mundo que acompañe a un modelo ideal de sociedad. Este conglomerado debe estar dotado, además, de coherencia y permanencia en el tiempo (Berstein, 1999, pp. 396-400). En la entrada que acompaña a la presente, Greppi (2021) también explicita la necesidad de restringir el foco de análisis excesivamente amplio al que invita el concepto, de cara a optimizar su «capacidad explicativa» y su «consistencia». A tal efecto, apuesta por la identificación de aquellos aspectos de las artes, la religión, las costumbres y las creencias colectivas que tengan una relación más explícita con el sistema político.

\section{Las virtudes epistémicas}

A pesar de estas prevenciones, y siempre que se tengan presentes las fronteras epistemológicas de la categoría, el concepto de cultura política se ha revelado como una herramienta heurística de primer orden. Ello precisamente por su capacidad para ampliar e interconectar toda una gama de variables inexploradas para el estudio de los hechos políticos. La irrupción de la categoría ha generado ya cuantiosos trabajos que han integrado el estudio clásico de las grandes biografías políticas y de los procesos institucionales con el análisis de un amplio abanico de fenómenos culturales.

Merece la pena mencionar algunos de dichos fenómenos que han sido oteados con éxito por parte de la producción académica reciente: los relatos de sentido que han estructurado históricamente los imaginarios y las estrategias de los grupos de poder (e.g. Ellenberger, 2015; Stahl, 2016; Rodríguez, 2019); Ios sistemas representacionales que le han otorgado contenido a los modelos de gobernanza, legitimidad, fiscalidad y legalidad vigentes en muy diversas épocas y contextos sociales (e.g. Vicent, 2019, pp. 403-423; Pines, 2012; Neely, 2005) ${ }^{6}$; las mutaciones y sedimentaciones conceptuales que han configurado los lenguajes filosóficos, religiosos, científicos, económicos, ecológicos, literarios, rituales y artísticos empleados para la producción y reproducción del poder (e.g. Walter, 2017; Chappey y Vincent, 2019, pp. 109-140; San Narciso Martín, 2015, pp. 191-207) ${ }^{7}$; los canales

\footnotetext{
${ }^{5}$ El extraordinario trabajo de Nancy Ellenberger explica cómo las aristocracias británicas de finales del siglo XIX emprendieron un proceso de re-imaginación de su estatus y su rol político para generar un nuevo «régimen emocional» que les permitiese lidiar con los acelerados cambios socioeconómicos que trajo el final de la era victoriana. Jason Stahl ha estudiado las dinámicas representacionales que permitieron la construcción de identificaciones aglutinantes y proyectos de reforma sistémica en los think tanks del conservadurismo norteamericano. Finalmente, la última obra de Jaime Edmundo Rodríguez ha sintetizado magistralmente los descubrimientos recientes en torno a los relatos teleológicos de legitimidad construidos por las élites políticas de la Monarquía imperial española en el contexto de las revoluciones liberales.

${ }^{6}$ Andrés María Vicent Fanconi ha estudiado cómo el endeudamiento de la Monarquía española durante el primer tercio del siglo XIX suscita toda una serie de discursos altamente emocionales, que, en base a un lamento nostálgico por el poder geopolítico perdido, estructuran un horizonte de reforma fiscal y política. Yuri Pines ha estudiado cómo los principios filosóficos del confucianismo y las prácticas de sociabilidad a él anexas se han proyectado sobre la política china en el largo plazo, modulando las lógicas de los sucesivos grupos de poder que han ocupado el Estado. Mark Neely ha estudiado cómo en el contexto de la guerra civil de los Estados Unidos una pléyade de literatos, asociaciones caritativas, iglesias y periódicos adaptaron sus respectivas prácticas y discursos a las necesidades políticas de la Unión.

7 John Walter ha estudiado cómo la introducción de nuevas fórmulas rituales vinculadas a los juramentos parlamentarios permitió la articulación de un discurso de signo radical-revolucionario que estuvo en la base de la guerra civil y la revolución inglesa del siglo XVII. Jean-Luc Chappey y Julien Vincent han examinado la íntima relación ideológica que los actores políticos de la Revolución francesa establecieron entre las enunciaciones de la ciudadanía y las representaciones de la naturaleza nacional, construyendo
} 
de comunicación (prensa, libro, radio, televisión, conferencias, rituales públicos, internet, etc.) y espacios de sociabilidad (escuela, ejército, sindicatos, clubes, cafés, sociedades económicas, etc.) que han permitido la circulación de significados políticos y la construcción de nuevos colectivos identitarios (étnicos, partidarios, sindicales, de género, etc.) (e.g. Velikanova, 2018; Müller, 2011; Hardacre, 2017) ${ }^{8}$; o los vínculos entre las muy plurales estrategias de articulación e interacción política observables históricamente a nivel local, regional e imperial y los universos de valores, lealtades y creencias en torno a los cuales se organizaban (e.g. Huzzey y Miller, 2020, pp. 1-43; Baker, 2015; Dench, 2018) ${ }^{9}$.

Los campos de estudio mentados han tenido éxito a la hora de trascender la conceptualización etnocéntrica y anclada en la democracia liberal con que han funcionado muchos acercamientos politológicos a la cultura política. Así lo diagnostica Jorge Eufracio Jaramillo (2017, p. 110), sugiriendo que ya en Almond y Verba subyace un fuerte componente valórico que considera como normativas a las culturas políticas vinculadas a la modernidad liberal y la participación democrática. Por el contrario, la aplicación del concepto a contextos temporales y espaciales cada vez más diversos ha permitido asociar la enorme versatilidad y mutabilidad de los sistemas políticos a la notable capacidad de las sociedades humanas para producir horizontes simbólicos ajustados a sus condiciones históricas de existencia. Estas aportaciones han incidido, necesariamente, en una expansión significativa de la cultura política, que ya no restringe su aplicación al universo de la democracia liberal representativa. El concepto se emplea, más bien, para lidiar con todos aquellos ámbitos de la cultura que inciden de forma directa en los mecanismos de cooperación grupal y articulación política en cualquier sociedad.

A su transversalidad y su aplicabilidad a distintos contextos espaciotemporales, el concepto añade otras evidentes ventajas epistémicas. En primer lugar, ofrece una vía intermedia entre el individualismo metodológico y el funcionalismo, puesto que pretende comprender las motivaciones psicológicas de los individuos a la par que identifica a las comunidades de sentido que determinan parcialmente la acción personal de estos (Berstein, 2003, pp. 11-12). Bajo el paraguas terminológico de las culturas políticas, los individuos se consideran como sujetos autónomos que actúan con un amplio margen de agencialidad, de libertad personal. Sin embargo, estos, a su vez, se imaginan desempeñando funciones y roles sociales

simbólicamente una verdadera «ecología republicana». David San Narciso Martín ha examinado los lenguajes de poder y legitimidad que articuló la Corte de Isabel II a través de sus ceremoniales cortesanos.

${ }^{8}$ Olga Velikanova ha estudiado las estrategias de socialización de significados políticos adoptadas por el Estado estalinista para penetrar en la subjetividad de los distintos sectores sociales de la Unión Soviética. Ya prefiguró este ejercicio Frank Lorenz Müller, que ha estudiado cómo la figura del emperador Federico III fue heroizada e iconizada para insertarse en los imaginarios de la sociedad alemana de su tiempo. Por último, es de especial interés la historia del sintoísmo escrita recientemente por Helen Hardacre, que ha explicado cómo éste está en la base de la cultura política japonesa, habiendo servido para estructurar los roles sociales, las actividades productivas y las relaciones de poder.

${ }^{9}$ Richard Huzzey y Henry Miller han estudiado cómo la petición al parlamento fue el medio preferente de interlocución política en la Inglaterra de Antiguo Régimen, lo que demuestra una cultura de interacción alternativa a la democracia electoral. Nicholas Baker demuestra cómo el tránsito de la Florencia renacentista de una república urbana a un ducado controlado por los Medici fue el resultado de la suma compleja de cambios capilares en la cultura política de su sociedad: la vestimenta, las relaciones de patronazgo, las jerarquías familiares o los lenguajes visuales fueron esenciales en el tránsito ideológico de la condición de ciudadanos a la de súbditos. Emma Dench hace un ejercicio similar al de Baker al evaluar cómo la expansión imperial afectó a todos los ámbitos de la cultura y la sociabilidad en la antigua Roma. 
necesariamente enmarcados dentro del universo de normas y creencias que les viene legado por la cultura política en que son socializados (Dueñas, 2010) ${ }^{10}$.

Esta teoría de la acción humana como mediación entre la agencia individual y los entramados conceptuales, institucionales e ideológicos en que se desenvuelve la misma es conciliable con las teorías de Chantal Mouffe (2005, pp. 8-34). La filósofa belga dibuja una línea divisoria entre «lo político», como dimensión de antagonismo, conflicto y cambio inserta en las relaciones humanas y "la política», que se referiría al basamento normativo que hace posible la coexistencia humana en condiciones de conflictividad $^{11}$. Si «lo político» constituye el campo en que los actores expresan su pluralidad y su agencialidad en una dinámica de pugna por el poder, «la política» es el espacio de los sistemas normativos y discursivos que fijan límites para dicha pluralidad. También algunos teóricos de los conceptos políticos, como Elías Palti (2014, pp. 387-405) o Pierre Rosanvallon (2003), han provisto de un marco de análisis que se asimila bien a esta postura. En ambos casos se afirma que los conceptos no tienen un significado o contenido fijado e intrínseco, sino que sirven como «índices de problemas», ítems sintácticos que permiten articular debates a partir de cierta comunalidad lingüística. En este contexto, la cultura política haría referencia tanto al campo discursivo configurado por las categorías compartidas por todos los miembros de una sociedad, como al juego retórico que implica la pugna entre distintas colectividades por fijar el significado de dichas categorías.

La categoría de cultura política también permite articular distintas escalas temporales, facilitando la combinación de análisis coyunturales de corte sincrónico con aproximaciones de tiempo largo. En este sentido, sus cultivadores entienden que los sistemas representacionales o marcos de sentido -frames- a que dan lugar las concepciones generales del mundo y de su evolución que configuran las culturas políticas serían el resultado de fenómenos de sedimentación histórica, es decir, estarían dotados de duración en función de procesos complejos de transmisión ideológica (Stoler, 2016). De hecho, son varios los trabajos que se han centrado en los procesos de aprendizaje y transmisión de las culturas políticas, enfocando sus estudios en los medios de socialización que garantizan su reproducción: partidos políticos, amistades, sindicatos, familias, etc. (e.g. Muñoz Tamayo, 2016) ${ }^{12}$. Ello ha implicado el abordaje de los «archivos culturales» que facilitan la transmisión intergeneracional de ciertos relatos de sentido y prácticas de poder, contribuyendo a la forja de identidades políticas y modelos normativos. Estas estructuras constituirían, precisamente, el sustrato de creencias, conceptos y valores en los cuales los sujetos serían socializados, enmarcando así su agencia individual (Palonen, 2017, pp. 96117).

La cultura política apela, además, al punto medio entre el materialismo y el idealismo. Esta no se concebiría como una mera expresión ideológica de los intereses objetivos preexistentes en los colectivos sociales. Tampoco como el resultado de la concreción de ciertos ideales abstractos en la vida social. La categoría se acercaría así a las teorías contextualistas de la escuela de Cambridge (Skinner, 2007, pp. 109126) y las teorías discursivas de corte postestructuralista (Foucault, 1988, pp. 111-

\footnotetext{
${ }^{10}$ El trabajo de Alcira Dueñas constituye un ejemplo de esta postura interpretativa, ya que estudia cómo una serie de escritores mestizos e indígenas prosperaron en la restrictiva república de las letras del virreinato del Perú e incluso en la Corte imperial de Madrid. Esto implicó un proceso dialéctico que supuso la adaptación y transformación mutua entre estos actores individuales y las instituciones que ocuparon. ${ }^{11}$ Esta distinción conceptual fue tomada por Mouffe de la obra de Julien Freund (2018 [1965]), uno de los introductores de la teoría de Carl Schmitt en Francia.

12 Es el caso de este magnífico trabajo de Víctor Muñoz Tamayo, en que estudia como la transmisión intergeneracional de valores y narrativas histórico-memorísticas en el seno de la familia ha sido fundamental en la vertebración ideológica de la Unión Democrática Independiente de Chile, así como en la organización efectiva de las redes clientelares que han fundamento su acceso al sistema político.
} 
112), puesto que sus empleadores tienden a entender que las ideas y los lenguajes de ellas derivados actúan en una relación de tensión dialéctica con los procesos materiales: ambas esferas de realidad se modelarían mutuamente (Welch, 2013, p. 78-84).

3. Actores y escalas: subculturas políticas, ideologías e imaginarios sociales

A pesar de sus evidentes excelencias heurísticas, la categoría que nos ocupa ofrece ciertas dificultades metodológicas irresueltas, precisamente como consecuencia de su carácter etéreo. Entre estas dificultades destaca la de la delimitación de la escala de los actores analizados. Ya se ha explicado cómo los estudios que asumen el contenido paradigmático de la cultura política basculan su atención entre los campos conceptuales que rigen en el conjunto de un sistema político y las apropiaciones pragmáticas que realizan de dichos vocabularios cada uno de los grupos que compiten y negocian en su seno. Ello implica que, en ocasiones, el término cultura política se refiera al conjunto de creencias y prácticas que rigen una sociedad o conjunto de sociedades y que, en otros casos, se refiera a un grupo específico (partidario, religioso, familiar, corporativo).

A tal efecto, algunos expertos se han decantado por recurrir al concepto de subcultura política. Almond y Verba ya lo acuñaron, entendiéndolo como un grupo o tendencia que comparte un conjunto específico de creencias, afinidades y actitudes en el seno de la cultura política correspondiente a toda una sociedad (Cabrera, 2010, pp. 43-47). Berstein, por su parte, entiende las subculturas políticas como agrupaciones o tendencias que proliferan en el seno de un sistema político (Berstein, 2003, pp. 14-15). La cultura política nacional actuaría, así, como denominador común, mientras que las subculturas políticas se constituirían como sus ramificaciones ideológicas, corporativas (académicas, militares, socio-profesionales, sindicales) o confesionales. Esta conceptualización entiende que las organizaciones políticas correspondientes a dichas subculturas son algo más que meras estructuras partidarias o nodos de poder: son grupos que comparten representaciones concretas del pretérito y el destino de la sociedad y que poseen mecanismos para su transmisión por medio de la tradición (Pocock, 2009, pp. 67-70).

A pesar de todo, la definición de las escalas analíticas sigue siendo enormemente plástica y ello supone cierta indeterminación a la hora de establecer los límites entre la «cultura» y la «subcultura». A efecto de obtener herramientas categoriales que permitan establecer con mayor precisión y utilidad dichas fronteras, sería sugerible recurrir a dos categorías que están ganando (o recuperando) un peso nada desdeñable en el campo de la nueva historia intelectual: la ideología y el imaginario social.

La propuesta podría parecer contradictoria, puesto que la asunción del concepto de cultura política residió originalmente en un intento de reemplazar la vieja noción de ideología, asociada (anacrónicamente) con interpretaciones de cuño materialista y marxista (Sargent, 2013, pp. 515-529). Esto comportaba partir de una definición muy restringida, que la entendía como un programa cerrado de normas de comportamiento, formas de pensamiento y objetivos políticos, el cual expresaba los intereses de un grupo de poder normalmente hegemónico. Afortunadamente, algunos representantes de la nueva historia de las ideologías políticas, como Michael Freeden (1996, p. 6) o Teun Van Dijk (2013, pp. 216-241), han ampliado y renovado el contenido semántico de esta categoría, recobrando su valor heurístico. Para estos, se podría entender la ideología como un entramado doctrinal de ideas, opiniones y actitudes que normalmente son sostenidas por grupos acotados y reconocibles, proveyendo directivas y planes de acción pública que pueden generar crítica social, 
orden o sentido de comunidad. No cabe duda de que esta significación es funcional a la idea de una subcultura política, puesto que hace referencia al entramado de representaciones y racionalidades particulares que caracterizan a un grupo, partido o movimiento político organizado.

Por el contrario, el concepto de imaginarios sociales tendría una significación más laxa, habiéndolo catalogado autores como John Rundell (2017, pp. 1-20) y Duncan Bell (2016, p. 94) como la forma en que todos los actores políticos de una sociedad conceptualizan su entorno sociocultural, generando modos de interacción pública y valores compartidos, así como identificaciones, relatos, imágenes y expectativas normativas que guían su existencia. El imaginario social reflejaría una concepción filosófica subyacente, que se podría traducir en varias ideologías concretas y coherentes o simplemente en un conjunto de reglas susceptibles de múltiples lecturas basadas en ciertos principios axiomáticos, como sería el caso del nacionalismo, el imperialismo, el liberalismo o el republicanismo (Escribano Roca, $2019^{a}$, pp. 381-401) ${ }^{13}$. El término se acercaría de manera muy clara al entendimiento de la cultura política como un conjunto de creencias y asunciones respecto del funcionamiento del sistema político que están arraigados en todos los grupos de una sociedad determinada, por más que puedan entrar en una dinámica de disputa ideológica. En el imaginario social podríamos identificar los campos conceptuales y las creencias comunes en los cuales habitan todos los miembros de una sociedad. Correspondiéndose con el conjunto de racionalidades de una cultura política, los imaginarios sociales actuarían como marcos de pugna ideológica entre las diversas subculturas políticas, permitiendo el despliegue de lo «político».

Si bien este cruce terminológico con la historia intelectual puede tener evidentes beneficios, no se debe olvidar que la cultura política no está arraigada en una ontología fundamental. Es decir, su escala es modelable en función de los intereses epistemológicos de aquel que la emplea. El cuarteto conceptual de ideología-subcultura política-imaginario social-cultura política debe ser cambiante en la medida en que las interacciones entre las representaciones individuales, grupales y sociales de lo político son enormemente complejas.

\section{Conciencia Histórica y cultura política: un modelo heurístico}

El estudio de las culturas políticas también ha mostrado en los últimos años una íntima relación con los análisis centrados en develar las formas de conciencia histórica de las sociedades modernas y premodernas, ya que pretende entender las relaciones conceptuales que los individuos y grupos establecen entre el pasado, el presente y el futuro (Rüsen, 2005, p. 168). La conciencia histórica se podría entender, así, como el ámbito que permite la «historización» de la experiencia temporal en el seno de una determinada cultura política. Siguiendo las nociones de la sociología del conocimiento de Norbert Elias y las teorías del giro temporal ${ }^{14}$, podría defenderse que la conciencia histórica se constituye como una práctica mental de síntesis y regulación, que permite a los individuos y comunidades humanas orientarse en un contexto de experiencias

\footnotetext{
${ }^{13}$ Rodrigo Escribano ha analizado cómo las élites intelectuales de la Unión Liberal emprendieron una serie de proyectos de edición documental que aspiraron a cimentar la construcción de una visión heroica y colonialista de la historia imperial española. Las colecciones documentales resultantes reflejaron un imaginario panhispanista que le dio pábulo a la socialización del imperialismo decimonónico. Este imaginario social tuvo, no obstante, diversas expresiones ideológicas, en la medida en que los intelectuales que emplearon estas colecciones documentales para construir sus respectivas versiones ideológicas del mito imperial: panhispanismo progresista, hispanismo conservador, nacionalcatolicismo. Bajo este supuesto el panhispanismo sería un imaginario social inserto en cultura política de la España decimonónica con distintas expresiones ideológicas asociadas a diversas subculturas políticas.

${ }^{14}$ Expresión que hace referencia al boom que han experimentado los estudios en torno a la temporalidad en el marco de la teoría de la historia y la historia intelectual.
} 
temporales complejas, con el fin de dotar de estabilidad ontológica y regularidad a la vida social (Elias, 1992, pp. 405-409). Esto se lograría a través de ejercicios intelectuales de sincronización conceptual y narrativa, que permitirían modelar simbólicamente el tiempo, significando las continuidades, aceleraciones, rupturas, ritmos y escalas temporales percibidas por un grupo social determinado (Jordheim, 2014, pp. 506-518).

Los seres humanos mediarían con la temporalidad natural de las horas, los días y los ciclos celestes y la convertirían en tiempo social a través de su organización cronológica (diacrónica) y de conceptos temporales generadores de simultaneidad (sincrónicos) como: «época», «siglo», «edad», «pasado», «presente» o «futuro» (Elías, 1992, pp. 20-36; Hölscher, 2014, pp. 577-591). Recurriendo a la psicología social, Ville Erkkila muestra cómo los procesos narrativos de construcción identitaria tienden a paliar la alteridad del pasado y a conectarlo a las sensibilidades, inquietudes y aspiraciones políticas de los miembros vivos de una comunidad (Erkkillä, 2015, pp. 602-620).

La importancia de las formas de conciencia histórica ha sido subrayada por estudios empíricos de gran calidad, los cuales han demostrado que las evocaciones de los héroes, triunfos y traumas del pasado son un recurso transcultural de primer orden en la producción de significados políticos e identificaciones grupales (Baena y Byker, 2015, pp. 259-269; Benesch, 2014; Torres, 2010) ${ }^{15}$. Por ello es posible aducir que el estudio de las culturas políticas es indisociable del abordaje de las culturas de la historia. Para Xavier Núñez Seixas (2017, pp. 56-72) y David Carr (2014, pp. 43), la cultura histórica denotaría el conjunto de relatos, canales de comunicación, espacios y actores que están implicados en la socialización de sentidos sobre el pasado en la esfera pública. Estos tendrían la función de organizar las vivencias temporales y las experiencias de historicidad de las colectividades humanas. Billie Melman, uno de los pioneros del paradigma, lo sintetiza afirmando que el estudio de la cultura histórica consiste en seguir: "the circulation of history between its images and the forms and social lives and meanings given to these images through procedures and practices of usage and, when possible, through the imagination and fantasy» (2006, p. 4).

En este sentido, el concepto de cultura histórica tiene la ventaja de permitir estudiar integradamente a todos los agentes mnemónicos que han podido estar implicados en la definición de imaginarios e ideas históricas: filósofos, literatos, historiadores, cineastas, sacerdotes, restauradores, políticos, pintores, arquitectos, activistas, científicos sociales, etc. Es decir, englobaría todo aquello que Ross Wilson ha denominado los «lenguajes del pasado»: el conjunto de enunciados históricos que quedan impresos en los imaginarios de las sociedades, modelando sus esquemas de pertenencia, sus códigos éticos, sus referentes identitarios y sus metas políticas (Wilson, 2016, pp. 1-21).

Al mismo tiempo, el paradigma de la conciencia histórica invita a un análisis koselleckiano de los conceptos políticos que operan en las culturas estudiadas, puesto que implica comprender la co-determinación temporal entre las experiencias

\footnotetext{
15 Por ejemplo, Rosalía Baena y Christa Byker han demostrado cómo el éxito de la serie Downtown Abbey se basa en explotar una conciencia histórica nostálgica, la cual interpela de forma particularmente eficaz a las audiencias británicas de la era de la privatización neoliberal y el euroescepticismo. Oleg Benesh estudió cómo la figura del samurái y la tradición del bushido fueron resignificadas míticamente por diversos proyectos políticos a lo largo de la historia contemporánea de Japón, con el claro fin de fidelizar a los ciudadanos y generar modelos de comportamiento colectivo. Por último, Ana Teresa Torres ha estudiado cómo la figura de Simón Bolívar ha sido sucesivamente reinventada por las fuerzas políticas y los colectivos sociales de Venezuela, legitimando en muchos casos una cultura que cifra la regeneración política del país en liderazgos extrainstitucionales y poderes pretorianos.
} 
compartidas del pasado, sus interpretaciones significativas (conceptualización y narración) y los horizontes de expectativas colectivas que generan (Koselleck, 2004, pp. 255-276). Es por ello que los análisis de las culturas políticas también son susceptibles de incorporar, en aras de la riqueza y la precisión conceptual, los aportes de los future studies, la utopología y la historiografía del futuro (Navajas Zubeldia, 2013, pp. 32-50). Estos campos han puesto énfasis en develar los modos en que los sistemas académicos y políticos se han afanado históricamente por vertebrar tecnologías culturales para la prospección e imaginación del futuro (Andersson, 2019, pp. 31-34 $)^{16}$. Los trabajos realizados desde este paradigma han demostrado que las disputas por el control simbólico y tecnológico del devenir colectivo son uno de los elementos esenciales en la conformación de las creencias y estrategias de una cultura política específica. Zoltan B. Simon, por ejemplo, explica cómo las prospecciones futuristas ofrecidas por el posthumanismo de signo ecologista, animalista y posmoderno implican un proyecto político antagónico al de los escenarios de futuro definidos por el transhumanismo de vocación tecnológica, científica y desarrollista (Simon, 2019, pp. 171-184).

Estas observaciones no van dirigidas a complejizar aún más el concepto de cultura política, sino precisamente a definir uno de sus aspectos esenciales (la conciencia histórica) y a sugerir en base a él un modelo heurístico que permita ordenar los análisis que asumen la categoría. Atendiendo a estos presupuestos, el estudio de las culturas políticas sería susceptible de responder a un análisis de tres niveles (Escribano, 2019b, pp. 124-152). En primer lugar, implicaría comprender las formas de experiencia compartidas, es decir, el modo en que los nuevos estímulos eventuales impactan en el archivo cultural de valores y creencias de un determinado individuo o grupo y el modo en que este se ve impelido a una respuesta argumentativa y emocional a los mismos (e.g. Grethlein, 2019). Recientemente ha habido notables contribuciones que se han centrado en el papel que determinadas experiencias históricas han jugado a la hora de reconfigurar en profundidad las cosmovisiones políticas de las sociedades del mundo. Sirvan de ejemplo el popular trabajo de Pankaj Mishra (2019) sobre las rapidísimas mutaciones provocadas por el imperialismo euroamericano en los viejos sistemas filosóficos del mundo asiático. También los magníficos estudios coordinados por Broecks, Hicks y Guimerá (2012), que han ilustrado cómo la explosiva expansión del imperio napoleónico alteró de manera irreversible los códigos normativos y formas de articulación política de los vastos espacios soberanos (la Monarquía imperial hispánica, los territorios italianos, Europa central y oriental) que se vieron penetrados por su particular cultura constitucionalimperial-revolucionaria.

En segundo lugar, se precisaría del estudio del nivel simbólico, es decir, de la interpretación que los colectivos sociales realizan de sus experiencias para otorgarles sentido político, engendrando lecturas comunes del pasado, proyecciones compartidas del futuro y modelaciones del horizonte ideal a perseguir. Este nivel implica, a su vez, tres dimensiones de análisis. Por un lado, supone estudiar las narrativas que elabora cada cultura política para generar una interpretación inteligible de las experiencias acumuladas. El análisis narratológico implicaría examinar los relatos, es decir, «la ordenación de los hechos en un espectáculo o proceso de los acontecimientos con comienzo, medio y fin» (White, 1992, p. 17). Ello supondría interpelar los procesos semióticos de selección y caracterización de los eventos, espacios, héroes y personajes que componen dichos relatos políticos. También implicaría analizar las estructuras tropológicas que dotan de poder explicativo a las

\footnotetext{
16 Jenny Andersson ha ofrecido una excelente historia en torno a los imaginarios prospectivos de la Guerra Fría, forjados en base a la organización de la futurología como disciplina que pretendía ofrecer una respuesta simbólica y tecnológica a las incertidumbres culturales de los grupos de poder.
} 
narrativas de la cultura política analizada: metáforas organicistas, mecanicistas, familiares o ecológicas que sirven como recursos figurativos para facilitar la comprensión de una red compleja de conceptos político-filosóficos (González de Requena Farré, 2016, pp. 289-290). Todo ello redundaría en un abordaje de los mitos y mitologemas políticos ${ }^{17}$ que, como narrativas simplificadoras que organizan la experiencia social, configuran el universo de creencias del grupo abordado (Campbell, 2019).

Al nivel narrativo se uniría el conceptual, es decir, un estudio semántico (diacrónico) y pragmático (sincrónico) de los conceptos políticos que pueblan los relatos de los grupos abordados. Sería preciso poner especial atención en las pugnas conceptuales que mantienen dichos grupos con sus pares, en las redes semánticas que constituyen la especificidad de sus vocabularios, en los procesos de circulación y traducción conceptual que los alteran y, por último, en los procesos de dicotomización que emergen en el seno del diccionario categorial de una cultura política (nosotros/los otros; dominador/dominado; violencia/justicia, etc.) (Escudier, 2013, pp. 305-350).

Por último, sería necesario incorporar un análisis argumentativo, valorar en qué argumentos, tesis e ideas maestras se derivan las narrativas y vocabularios analizados (Kuukkanen, 2015, pp. 131-147). Todas estas dimensiones constituirían el nivel propiamente simbólico para el análisis de una cultura política dada. El resultado de su aplicación sería poder interpelar organizadamente el sistema de creencias abordado, incorporando, además, su expresión emocional.

En este sentido, se pueden aplicar al estudio del plano simbólico los desarrollos de la neurociencia y de la historia de las emociones, que han establecido vinculaciones de gran interés entre los procesos cognitivos, las identidades grupales y los mecanismos emocionales. Se entenderían las emociones como tendencias empáticas espontáneas que surgen de los sistemas espejo de nuestros cerebros. Estas guían nuestros juicios morales y dan fuerza motivacional para conducir la acción (Meiselman, 2016, pp. 7-8). Desde este punto de vista, los sistemas representacionales vertebrados por las culturas políticas contribuirían a crear medioambientes emocionales, que incidirían en las respuestas empáticas de sus miembros ante los estímulos experienciales y conceptuales que reciben (González Manso, 2013, pp. 12-30).

El tercer nivel de análisis (tras el experiencial y el simbólico) estaría comprendido por la dimensión performativa de la cultura o subcultura política analizada. Es decir, por las estrategias comunicacionales y retóricas mediante las cuales las experiencias compartidas y sus interpretaciones significativas son socializadas (a través de discursos escriturarios, orales, rituales y visuales), generando actitudes y modos de acción colectiva. En este contexto, y atendiendo a las teorías de la comunicación, la cultura política consistiría en todo un sistema de actos del habla dirigidos a fines muy específicos: añadir didácticamente nuevas representaciones internas en la mente de sus miembros actuales y potenciales (intención informativa); modificar las ya existentes (intención persuasiva); lograr que el receptor modifique sus modos de actuar (intención directiva) o imponer jerárquicamente sus representaciones a otras alternativas apelando a la normatividad de su discurso (intención normativa) (Escandell Vidal, 2014). Las representaciones emergidas en el seno de una cultura política estarían dotadas de fuerza perlocucionaria o de «energía social», es decir, de capacidad para transformar las

\footnotetext{
17 Una estructura narrativa que tiende a repetirse en los grandes relatos míticos, como los ciclos de nacimiento, muerte y resurrección en los imaginarios nacional-imperiales.
} 
percepciones y experiencias de sus miembros (Pocock, 2009, pp. 67-70; Chartier, 2007, pp. 83-86).

Atendiendo a la conceptualización clásica de Almond y Verba, sería en este nivel performativo donde la cultura política funcionaría como «un vínculo causal entre la realidad política y la conducta política» (Cabrera, 2010, p. 23). Se entiende así que la dimensión performativa de las culturas políticas cumpliría una serie de funciones fundamentales, entre las que se podrían destacar las de carácter preservativo, justificativo, identificativo y orientativo. La función identificativa consistiría en la actividad de generar sentimientos y sentidos de pertenencia que conecten al individuo con los grupos y estructuras de poder en las que se ve inmerso, permitiéndole trascender su propia particularidad y facilitando su adscripción a distintas comunidades éticas y políticas que trascienden la temporalidad presente (Paul, 2015, p. 129). La función justificativa dotaría de legitimidad a ciertas instituciones y prácticas vigentes, normalizándolas a partir de procesos de autentificación y estabilización (Winter, 2010, p. 19-21). A estas se añadiría la función preservativa, que consistiría en la conservación, organización y recuperación activa de experiencias y prácticas tradicionales que permitirían una transferencia intergeneracional de conocimientos y costumbres (Day, 2008, p. 419-420). Finalmente, la cultura política tendría una función orientativa, en la medida en que la interpretación colectiva de los acontecimientos políticos define los medios y los fines de acción que debe emplear un grupo dado para la consecución de sus aspiraciones, encarnadas en un set de expectativas, horizontes ideales y esperanzas (que a su vez son fruto de una lectura en clave anticipativa de su contexto presente y pasado) (Koselleck, 2003, p. 73-96).

\section{Culturas políticas, nacionalismos y visiones de lo global}

El modelo hasta aquí descrito presenta evidentes ventajas a la hora de organizar la disección de la enorme multiplicidad de variables que lega el concepto de cultura política. Sin embargo, no puede desconocer que hay otros campos de reflexión que ya han fijado muchas estrategias aplicables a la mejor definición y disección de la categoría. Entre estos destacan los estudios del nacionalismo y los análisis intelectuales de la historia de las relaciones exteriores y la política mundial.

Los estudios del nacionalismo, especialmente pujantes desde el triunfo del paradigma modernista a partir de los años 80 , tienen una evidente relación con el problema de las culturas políticas. El interés por los entramados culturales que enmarcan el poder político coincide con la concepción del nacionalismo como una religión cívica que actuó como horizonte sustitutivo ante los procesos de quiebre confesional y secularización acontecidos en el mundo Atlántico del siglo XVIII y ante la consiguiente crisis de los sistemas de legitimidad de Antiguo Régimen (Anderson, 1993). Las abundantísimas aproximaciones paradigmáticas al problema del nacionalismo, bien reflejadas en las sucesivas publicaciones de revistas como Nations and Nationalism y National Identities, se han aplicado al análisis de todos los fenómenos ideológicos, narrativos, psicológicos y comunicativos que interesan a los estudiosos de las culturas políticas. Por supuesto, la diferencia esencial es que estos han centralizado su atención en la idea de nación, dejando como variables dependientes muchos otros conceptos políticos (e.g. civilización, raza, soberanía, justicia) y sistemas ideológicos (e.g. liberalismo, cosmopolitismo, doctrinarismo, arielismo) que se sitúan en el centro de reflexión en los estudios vehiculados por la categoría que nos ocupa.

En lo referente a la socialización y reproducción cultural de significados políticos, las teorías del nacionalismo banal y de la nacionalización han ofrecido modelos aplicables para el análisis de las culturas políticas. Estas tendencias han 
establecido modelos heurísticos bien cimentados y escalonados, que facilitan el abordaje de la circulación de los imaginarios de nación en la esfera pública (administraciones estatales, escuelas, instituciones), la esfera semipública (asociaciones civiles, partidos, clubes, iglesias, sindicatos) y la esfera privada (familias, amistades, grupos de ocio) (Quiroga 2013, pp. 17-38). Ello ha comportado un notable avance en la comprensión de las hondas raíces culturales de las políticas nacionalistas, tanto a nivel del Estado-nación como en otros muy diversos ámbitos de sociabilidad y de poder. Sirvan de ejemplo algunos magníficos trabajos que recientemente han abordado la imbricación entre los tropos culturales del nacionalismo y las dinámicas de competencia empresarial e interestatal en el marco del mercado mundial (Turner, 2016, p. 14-26). También son de destacar algunos otros que han abordado la importancia del nacionalismo gastronómico, el musical o el deportivo como ámbitos de producción y reproducción de identidades políticas (cf. MacLean y Field 2014, pp. 283-289; Ichijo y Ranta, 2016; Leerssen, 2014, pp. 606$627)$.

Por supuesto, el estudio de las culturas políticas tiene mucho que aprender de los estudios del nacionalismo, pero también mucho que aportar. El carácter más capilar y transversal de la aproximación a las culturas políticas, supondría entender las complejas interacciones entre la agencia individual, grupal y social que suceden en el seno de determinado movimiento nacionalista. Su aplicación permitiría investigar cuántas culturas y subculturas políticas actúan en la coyuntura abordada y cuáles son sus dinámicas de solapamiento y conflicto. Esto puede ayudar a entender que el Estado-nación no es ni mucho menos la única instancia de autoridad e identidad en la historia contemporánea y que ésta se forja a partir de una heteronomía muy compleja de poderes, cada uno de ellos respaldado por sus propios sistemas de legitimidad, representación y comportamiento (Sábato, 2019) ${ }^{18}$. También implica abordar las constantes hibridaciones entre los imaginarios nacionales y otros sistemas ideológicos y valóricos de raigambre local, regional o transnacional que fueron igual de fundamentales que el nacionalismo en la modelación de la contemporaneidad política (globalismo, neoliberalismo, socialismo, islamismo, sintoísmo, y un larguísimo etcétera) (Escribano Roca, 2018, pp. 55-70) ${ }^{19}$.

La cultura política también ofrece un gran valor como herramienta categorial para el análisis de las relaciones internacionales. Recientemente, una nueva tendencia de historia intelectual con vocación globalista se ha interesado por entender las formas de representación del espacio mundial y la sociedad internacional que guiaron a los Estados y colectividades transnacionales del pasado. Alejándose del realismo interpretativo y de las teorías de la acción racional aplicadas a la comprensión de la política exterior, estos autores se han centrado en estudiar el conjunto de narrativas, metáforas, conceptos, argumentos y rituales que permitieron a los actores sociales del pasado perfilar una imagen totalizadora del globo. La configuración cultural de estos imaginarios geopolíticos implicaría el establecimiento de un sistema de creencias normativas respecto al poder mundial (e.g. Dittmer y Bos 2019), a las formas de interacción entre las potencias (e.g. Armitage 2013), a los modos legítimos y deseables de territorialización y soberanía (i.a. Mazower, 2018), y a las dinámicas idóneas de interacción entre las sociedades humanas y las ecologías planetarias (Barton, 2007). Las representaciones culturales también se habrían configurado como un elemento esencial en la formulación de estrategias de poder

\footnotetext{
18 Hilda Sábato ha subrayado la pluralidad de actores y espacios de poder ajenos al ejecutivo nacional que participaron en los primeros experimentos republicanos latinoamericanos.

${ }^{19}$ Rodrigo Escribano realizó una reflexión en torno a la diversidad de lenguajes de legitimidad y sistemas de poder que convivieron con el nacionalismo en el largo siglo XIX.
} 
blando y en la producción de recursos simbólicos funcionales al mismo (e.g. Louw, 2016, pp. 147-161).

Todos estos ítems han sido agrupados por Duncan Bell (2013, pp. 264-282; 2007, pp. 2-26) bajo el concepto de visiones de lo global y por Manfred Steger (2009) bajo la categoría de imaginarios globales. Subyace en estos autores la convicción de que las dinámicas del poder global no son discernibles si nos centramos únicamente en los intereses «objetivos» que los actores internacionales conceptualizaron con arreglo a factores económicos y geoestratégicos. Como ha defendido con lucidez Lauren Goodlad (2015), los intereses se conceptualizan con recurso a estructuras metafóricas con connotaciones éticas y estéticas que forman parte del terreno de la subjetividad y que son esenciales para dotar de sentido a las experiencias y las expectativas que guían la política exterior. De ahí que los análisis derivados del estudio de las culturas políticas sean necesarios para rastrear los universos de sentido que modelaron las dinámicas de poder de la mundialización y colmar así las demandas de renovación de la teoría de las relaciones internacionales (Guilhot, 2019, pp. 4-8).

\section{Conclusión}

La categoría de cultura política se ha consolidado en las últimas décadas como un instrumento de gran utilidad para reconciliar las agendas analíticas de la historia intelectual, la historia política y la historia social, así como para poner a estas a dialogar con otras disciplinas, principalmente la ciencia política y la sociología. Cuando se aplica al análisis historiográfico, el potencial esencial del concepto radica en su propuesta de situar en un mismo plano de análisis el mundo las representaciones simbólicas y las prácticas políticas.

Dicha ontología dualística ha comportado toda una serie de virtudes epistémicas, las cuales han sido identificadas de acuerdo a una revisión bibliográfica de los trabajos historiográficos que han aplicado la categoría. Entre dichas ventajas epistemológicas, se ha destacado su capacidad para analizar dialécticamente los procesos político-institucionales junto a las representaciones culturales que los mediatizan, permitiendo así trascender los marcos eurocéntricos y presentistas, que tendían a atribuir significados normativos y mecanicistas (asociados teleológicamente al triunfo de la democracia liberal) a los hechos políticos. Junto a esta virtud se han expuesto otras. En primer lugar, su capacidad para conciliar el individualismo metodológico con enfoques funcionalistas, permitiendo considerar dialécticamente la agencia de los actores particulares y el papel de los marcos institucionales, legales e ideológicas en que estos son socializados. Se evita así la caída en los excesos del psicologicismo y del determinismo estructuralista. En segundo lugar, se ha subrayado la utilidad del término para vehicular análisis que consideren distintas escalas temporales, puesto que su empleo invita a prestar atención tanto a las rupturas introducidas por determinados actos y fenómenos políticos coyunturales, como a los precedentes estructurales que los enmarcan y condicionan. Por último, se ha subrayado la importancia que le otorgan los usos paradigmáticos del concepto a poner en diálogo los procesos ideológicos y materiales, considerándolos en una relación de co-determinación que trasciende las jerarquías idealistas y materialistas. Se podría afirmar, así, que las virtudes epistémicas de la categoría consisten en introducir la complejidad analítica en la teoría de la acción humana, las escalas temporales y las relaciones entre materialidad y discurso.

Tras la revisión de las propuestas investigativas a que da lugar, queda la sensación de que la categoría de cultura política no propone nada sustantivamente nuevo, sino más bien una reversión de los procesos de compartimentación 
epistemológica derivados de la excesiva especialización disciplinar y sub-disciplinar acontecida en las Ciencias Sociales y las Humanidades a lo largo del siglo XX. El uso de la categoría a nivel historiográfico constituiría de facto a una refundación de los proyectos intelectuales que aspiraron a entender moral, política, filosofía, costumbre, religión y derecho como un entramado indisociable (e.g. PlatónAristóteles-Hobbes-Tocqueville-Gramsci-Weber). No obstante, esta transversalidad implica el peligro no menor de la ubicuidad y de la indefinición: la aplicación indiscriminada del concepto a todos los hechos sociales y culturales tendería a transformarla en un significante vacío y analíticamente inservible. Es por ello que el presente escrito ha subrayado el valor de los ejercicios de acotación conceptual llevados a cabo por Serge Berstein y Andrea Greppi. Estos, básicamente, defienden la identificación de ciertos atributos que delimiten los objetos catalogables en el rango de las culturas políticas: colectividades reconocibles, referentes míticos e históricos comunes, sistemas éticos y filosóficos reconocibles y modelos ideales de sociedad, todo ello bajo la premisa de que las narrativas y manifestaciones culturales abordadas deben tener una relación evidente con el sistema político.

De cualquier modo, la presente reflexión se ha fundamentado en la proposición de que, para evitar el mal de la laxitud terminológica y metodológica y aprovechar el amplio abanico de potencialidades investigativas de la categoría, no solo basta con su acotación conceptual. Es asimismo necesario definir modelos heurísticos más precisos en base a su conexión con campos de estudio que gozan ya de un amplio desarrollo paradigmático y metodológico. En este sentido, el tercer apartado ha sugerido que la aplicación de las categorizaciones de imaginario social e ideología, provenientes de la nueva historia intelectual, pueden servir como una herramienta útil para definir las problemáticas escalas de análisis sobre las que opera el concepto abordado. Estas pueden permitir diferenciar con mayor exactitud el marco general de la cultura política de una sociedad dada de las subculturas políticas articuladas por los grupos de poder e interés que operan en su seno. Del mismo modo, el cuarto apartado ha servido para exponer cómo el marco teórico-metodológico de los estudios sobre la temporalidad y la conciencia histórica puede servir para optimizar los análisis de los relatos, las experiencias colectivas y las expectativas compartidas que tanto inciden en la configuración de la categoría que nos ocupa. Esta perspectiva ha permitido diseñar un modelo heurístico de tres niveles, que invita al análisis integrado de los planos experienciales, simbólicos y performativos que configuran la conciencia histórica de las culturas políticas.

El último apartado ha mantenido el mismo tono propositivo, en este caso sugiriendo cómo el concepto de cultura política puede enriquecer y profundizar las estrategias analíticas de los estudios del nacionalismo. Esto especialmente favoreciendo que los abordajes del fenómeno nacionalista sitúen a este en un contexto más transversal, poniéndolo en diálogo con otros conceptos políticos y sistemas de creencias que acompañaron su desarrollo. Al mismo tiempo, se ha reivindicado que los modelos teórico-metodológicos elaborados por las teorías de la nacionalización y del nacionalismo banal se pueden emplear de forma eficiente para vehicular los análisis de los procesos de socialización de las culturas políticas. Finalmente, se ha apostado por una profundización en la todavía embrionaria aplicación de la categoría que nos ocupa al abordaje del papel de las representaciones culturales en las dinámicas del poder mundial.

Es posible concluir que, para aprovechar en su plenitud las virtudes epistémicas del concepto de cultura política es necesario continuar profundizando y concretando los modelos heurísticos y metodológicos que son susceptibles de delimitar su aplicación historiográfica. Dicha concreción no puede restringirse a la reflexión teorética, sino que debe fundamentarse en un diálogo de la categoría con 
campos de estudio y paradigmas que comparten problemáticas anexas a la misma y que ofrecen un notable desarrollo en la definición de sus objetos y sus estrategias analíticas.

Bibliografía

Almond, G. A., \& Verba, S. (2016). The civic culture: Political attitudes and democracy in five nations. Princeton: Princeton Univ. Press.

Anderson, B. R. O. (1993). Comunidades imaginadas: Reflexiones sobre el origen y la difusión del nacionalismo. México: FCE.

Andersson, J. (2018). The Future of the World: Futurology, Futurists, and the Struggle for the Post Cold War Imagination. Oxford: Oxford University Press.

Armitage, D. (2013). Foundations of Modern International Thought. Cambridge: Cambridge University Press.

Baena, R. y Byker, B. (2015). Dialects of nostalgia: Downton Abbey and English identity. National Identities 17, pp. 259-69. DOI: https://doi.org/10.1080/14608944.2014.942262 .

Baker, K. (2006). El concepto de cultura política en la reciente historiografía sobre la Revolución Francesa. Ayer, 62, pp. 89-110.

Baker, N. S. (2013). The Fruit of Liberty: Political Culture in the Florentine Renaissance, 1480-1550. Harvard: Harvard University Press.

Baring, E. (2016). Intellectual History and Poststructuralism. In R. Whatmore \& B. Young (Eds.), A companion to intellectual history (pp. 48-60). Malden MA: Blackwell.

Barton, G. A. (2007). Empire forestry and the origins of environmentalism. Cambridge: Cambridge Univeristy Press.

Bell, D. (2013). Making and Taking Worlds. In S. Moyn \& A. Sartori (Eds.), Global Intellectual history (pp. 254-282). Columbia University Press. http://public.eblib.com/choice/publicfullrecord.aspx?p=1103450.

Bell, D. (2016). Reordering the world: Essays on liberalism and empire. Princeton, N.J.; Oxford: Princeton university press.

Benesch, O. (2014) Inventing the Way of the Samurai: Nationalism, Internationalism, and Bushido in Modern Japan. Oxford: Oxford University Press.

Berstein, S. (1999). La cultura política. In J.-P. Rioux \& J.-F. Sirinelli (Eds.), Para una historia cultural (pp. 389-405). México: Taurus.

Berstein, S. (2003). Nature et fonction des cultures politiques. In S. Berstein (Ed.), Les cultures politiques en France (pp. 11-36). París: Seuil.

Broers, M., Hicks, P., \& Guimerá, A. (2012). The Napoleonic Empire and the New European Political Culture. London: Palgrave Macmillan UK.

Cabrera, M. Á. (2010). La investigación histórica y el concepto de cultura política. In M. Pérez Ledesma \& M. Sierra (Eds.), Culturas políticas: Teoría e historia (pp. 19-80). Zaragoza: Institución Fernando el Católico.

Campbell, J. (2019). El poder del mito. Madrid: Capitán Swing.

Carr, D. (2014). Experience and history: Phenomenological perspectives on the historical world. Oxford: Oxford University Press.

Chappey, J.-L., \& Vincent, J. (2019). A Republican Ecology? Citizenship, Nature and the French Revolution (1795-1799)*. Past \& Present, 243(1), pp. 109-140. https://doi.org/10.1093/pastj/gtz003.

Chartier, R. (2007). El pasado en el presente. Co-herencia, 4(7), pp. 83-102.

Day, M. (2008). Our Relations with the Past. Philosophia, 36, pp. 417-427.

Dench, E. (2018). Empire and political cultures in the Roman world. Cambridge: Cambridge University Press.

Dittmer, J., \& Bos, D. (2019). Popular culture, geopolitics, and identity. New York: Rowman \& Littlefield.

Dueñas, A. (2010). Indians and Mestizos in the"Lettered City": Reshaping Political 
Justice, Social Hierarchy, and Political Culture in Colonial Peru. Boulder: University Press of Colorado.

Ellenberger, N. (2015). Balfour's World: Aristocracy and Political Culture at the Fin de Siècle. London: Boydell \& Brewer.

Erkkilä, V. (2015). Time, identity, and history: On the cognitive psychology and figural practice of historiography. Rethinking History, 19(4), pp. 602-620. https://doi.org/10.1080/13642529.2015.1030229.

Escandell Vidal, M. V. (2014). La comunicación: Lengua, cognición y sociedad. Madrid: Akal.

Escribano Roca, R. (2018). Poderes mutantes. La sospechosa ausencia del EstadoNación durante el largo siglo XIX (1776-1914). In P. Pérez Herrero \& E. Cavieres Figueroa (Eds.), ¿ Sin pasado ni futuro? El presente pensado desde la historia y las ciencias sociales (pp. 55-70). Madrid: Marcial Pons.

Escribano Roca, R. (2019a). Ediciones Imperiales: La Colección de documentos inéditos relativos a las posesiones españolas en América y Oceanía y la construcción de un pasado panhispánico (1864-1936). Journal of Spanish Cultural Studies, 20(4), 2 pp. https://doi.org/10.1080/14636204.2019.1689683

Escribano Roca, R. (2019b). Experience, symbol and communication: A transversal model for the study of historical thought. História da Historiografia: International Journal of Theory and History of Historiography, 12(29), pp. 124-152. https://doi.org/10.15848/hh.v12i29.1335.

Escudier, A. (2013). Temporalización (Verzeitlichung) y modernidad política: Ensayo de sistematización a partir de R. Kosselleck. In J. Fernández Sebastián \& G. Capellán de Miguel (Eds.), Conceptos políticos, tiempo e historia: Nuevos enfoques en historia conceptual (pp. 303-350). Santander; Madrid: Editorial de la Universidad de Cantabria; McGraw-Hill Interamericana de España.

Eufracio Jaramillo, J. F. (2017). La cultura y la política en la cultura política. Nueva Antropología. Revista de Ciencias Sociales, 30(86), pp. 101-119.

Farré, J. A. G. De R. (2016). La recurrencia de la metáfora. Un marco filosóficolingüístico. Alpha: revista de artes, letras y filosofía, 43, pp. 289-302.

Foucault, M. (1988). La arqueología del saber. México: Siglo veintiuno editores.

Freeden, M. (2013). Political ideologies in the age of globalization. In L. T. Sargent \& M. Stears (Eds.), The Oxford Handbook of Political Ideologies (pp. 216-241). Oxford: Oxford University Press.

Freund, J. (2018 [1965]). La esencia de lo político. Madrid: Centro de Estudios Políticos y Constitucionales.

González Manso, A. I. (2015). Héroes nacionales como vehículos emocionales de conceptos. Historiografías: revista de historia y teoría, 10, pp. 12-30.

Goodlad, L. M. E. (2017). The Victorian geopolitical aesthetic: Realism, sovereignty, and transnational experience. Oxford: Oxford University Press.

Greppi, A. (2020). Cultura Política. Eunomía, En prensa.

Grethlein, J. (2019). Experience and History: The Reach and Limits of Phenomenological Approaches to History. History and Theory, 58(2), pp. 302312. https://doi.org/10.1111/hith.12116.

Guilhot, N. (2019) «Introduction» en Historiographical Investigations in International Relations, editado por Brian C. Schmidt y Nicolas Guilhot. London: Palgrave Macmillan.

Hardacre, H. (2017). Shinto: A history. Oxford: Oxford University Press.

Hölscher, L. (2014). Time Gardens: Historical Concepts in Modern Historiography. History and Theory, 53(4), pp. 577-591. https://doi.org/10.1111/hith.10732.

Huzzey, R., \& Miller, H. (n.d.). Petitions, Parliament and Political Culture: Petitioning the House of Commons, 1780-1918. Past \& Present, 248(1), pp. 123-164. https://doi.org/10.1093/pastj/gtz061

Jordheim, H. (2014). Introduction: Multiple Times and the Work of Synchronization. 
History and Theory, 53(4), pp. 498-518. https://doi.org/10.1111/hith.10728.

Koselleck, R. (2003). Aceleración, prognosis y secularización. Valencia: Pre-Textos.

Kuukkanen, J.-M. (2015). Postnarrativist philosophy of historiography. London: Palgrave Macmillan.

Leerssen, J. (2014). Romanticism, music, nationalism. Nations and Nationalism, 20(4), pp. 606-627. https://doi.org/10.1111/nana.12087.

Louw, E. (2016). South African Nation Branding and the World Cup: Promoting Nationalism, Nation Branding, and the Miracle Nation Discourse. In Z. Volcic \& M. Andrejevic (Eds.), Commercial Nationalism: Selling the Nation and Nationalizing the Sell (pp. 147-161). London: Palgrave Macmillan.

Lovejoy, A. O. (1983). La Gran cadena del ser. Barcelona: Icaria.

Maclean, M., \& FIELD, R. (2014). Performing nations, disrupting states: Sporting identities in nations without states. National Identities, 16(4), pp. 283-289. https://doi.org/10.1080/14608944.2014.930427.

Mazower, M. (2018). Gobernar el mundo: Historia de una idea desde 1815. Valencia: Barín Libros.

Meiselman, H. L. (2016). Emotion measurement. Duxord: Woodhead.

Melman, B. (2006). The Culture of History: English Uses of the Past 1800-1953. Oxford: Oxford University Press. http://ebookcentral.proquest.com/lib/uwsau/detail.action?doclD=431118.

Mishra, P. (2019). De las ruinas de los imperios: La rebelión contra Occidente y la metamorfosis de Asia. Barcelona: Galaxia Gutenberg.

Morán, M. L. (2010). Cultura política: Nuevas tendencias en los análisis sociopolíticos. In M. Pérez Ledesma \& M. Sierra (Eds.), Culturas políticas: Teoría e historia (pp. 87-131). Zaragoza: Institución Fernando el Católico.

Mouffe, C. (2005). On the Political. London: Routledge.

Müller, F. L. (2011). Our Fritz: Emperor Frederick III and the Political Culture of Imperial Germany. Harvard: Harvard University Press.

Muñoz Tamayo, V. (2016). Historia de la UDI: Generaciones y cultura política (19732013). Santiago de Chile: Ediciones de la Universidad Alberto Hurtado.

Navajas Zubeldía, C (2013). Sobre el tiempo histórico. Historiografías: revista de historia y teoría, 5, pp. 32-50.

Neely, M. E. (2005). The Boundaries of American Political Culture in the Civil War Era. North Carolina: The University of North Carolina Press.

Ohara, J. R. M. (2017). Virtudes Epistêmicas na Prática do Historiador: O caso da sensibilidade histórica na historiografia brasileira (1980-1990). História da Historiografia, 22, pp. 170-183. https://doi.org/10.15848/hh.v0i22.1107.

Palonen, K. (2017). Concepts and Debates: Rhetorical Perspectives on Conceptual Change. In W. Steinmetz, M. Freeden, \& J. Fernández Sebastián (Eds.), Conceptual history in the European space (pp. 96-117). New York; Oxford: Berghahn Books.

Palti, E. J. (2014). The "theoretical Revolution" in Intellectual History: From the History of Political Ideas to the History of Political Languages. History and Theory, 53(3), pp. 387-405. https://doi.org/10.1111/hith.10719.

Paul, H. (2016). La llamada del pasado: Claves de la teoría de la historia. Zaragoza: Institución Fernando el Católico.

Pedersen, S. (2007). What is Political History Now? In D. Cannadine (Ed.), What is history now? (pp. 36-56). London: Palgrave.

Pines, Y. (2012). The Everlasting Empire: The Political Culture of Ancient China and Its Imperial Legacy. Princeton: Princeton University Press.

Pocock, J. G. A. (2009). Political thought and history: Essays on theory and method. Cambridge: Cambridge University Press.

Quiroga Fernández-Soto, A. (2013). La nacionalización en España. Una propuesta teórica. Ayer, 90, pp. 17-38.

Roberts, D. D. (2017). Postmodernism, Social Science, and History: Returning to an 
Unfinished Agenda. History and Theory, 56(1), pp. 114-126. https://doi.org/10.1111/hith.12008

Rodríguez, J. E. (2018). Political Culture in Spanish America. Lincoln: UNP Nebraska.

Romeo Mateo, M. C., \& Sierra Alonso, M. (2014). La España liberal: 1833-1874. Madrid: Marcial Pons.

Rosanvallon, P. (2003). Por una historia conceptual de lo político. México: Fondo de Cultura Económica.

Rundell, J. (2017). Imaginaries of Modernity: Politics, Cultures, Tensions. London: Routledge.

Rüsen, J. (2005). History: Narration, interpretation, orientation. Berghahn Books.

Sábato, H. (2018). Republics of the New World: The revolutionary political experiment in nineteenth-century Latin America. Princeton: Princeton University Press.

San Narciso Martín, D. (2015). Ceremonias de la monarquía isabelina. Un análisis desde la historia cultural. REVISTA DE HISTORIOGRAFÍA (RevHisto), pp. 191207.

Sargent, L. T. (2013). Ideology and Utopia. In M. Freeden \& L. T. Sargent (Eds.), The Oxford Handbook of Political Ideologies (pp. 515-529). Oxford: Oxford University Press.

Seixas, P. C. (2017). Historical Concioussness and Historical Thinking. In M. Carretero, S. Berger, \& M. Grever (Eds.), Palgrave Handbook of Research in Historical Culture and Education (1st ed., pp. 59-72). London: Palgrave Macmillan UK.

Sewell, W. H. (2006). Por una reformulación de lo social. Ayer, 62, pp. 51-72.

Simon, Z. B. (2019). Two Cultures of the Posthuman Future. History and Theory, 58(2), pp. 171-184. https://doi.org/10.1111/hith.12108.

Skinner, Q. (2007). Motivos, intenciones, interpretación. In R. del Aguila \& E. Bocardo Crespo (Eds.), El Giro contextual: Cinco ensayos de Quentin Skinner, y seis comentarios (pp. 109-126). Madrid: Tecnos.

Stahl, J. (2016). Right Moves: The Conservative Think Tank in American Political Culture since 1945. North Carolina: University of North Carolina Press.

Steger, M. B. (2009). The rise of the global imaginary: Political ideologies from the French revolution to the global war on terror. Oxford: Oxford University Press.

Stoler, A. L. (2016). Duress. Durham: Duke University Press. http://read.dukeupress.edu/content/duress.

Tong, D. (2019). Introduction to Comparative Political Culture (1st ed.). Singapore: Springer Singapore.

Torres, A. T. (2010). La herencia de la tribu: del mito de la Independencia a la revolución bolivariana. Caracas: Ed. Alfa.

Turner, G. (2016). Setting the Scene for Commercial Nationalism: The Nation, the Market, and the Media. In Z. Volcic \& M. Andrejevic (Eds.), Commercial Nationalism: Selling the Nation and Nationalizing the Sell (pp. 14-26). London: Palgrave Macmillan.

Van Dijk, T. (2013). Ideology and Discourse. In M. Freeden, L. T. Sargent, \& M. Stears (Eds.), The Oxford Handbook of Political Ideologies (pp. 216-241). Oxford: Oxford University Press.

Velikanova, O. (2018). Mass Political Culture Under Stalinism (1st ed.). London: Springer International Publishing; Palgrave Macmillan.

Walter, J. (2017). Covenanting Citizens: The Protestation Oath and Popular Political Culture in the English Revolution (First edition). Oxford: Oxford University Press.

Welch, S. (2013). The Theory of Political Culture. Oxford: Oxford University Press.

White, H. V. (1992). El contenido de la forma: Narrativa discurso y representación histórica. Barcelona: Paidós.

Wilson, R. J. (2016). The language of the past. London: Bloomsbury Publishing Plc.

Winter, J. (2010). Introduction. The performance of the past: Memory, history, identity. 
In K. Tilmans, F. van Vree, \& J. Winter (Eds.), Performing the past: Memory, history, and identity in modern Europe (pp. 11-34). Amsterdam; Manchester: Amsterdam University Press ; Manchester University Press. 